\title{
DAMAGE TO III-V DEVICES DURING ELECTRON CYCLOTRON RESONANCE CHEMICAL VAPOR DEPOSITION
}

J.W. Lee ${ }^{(1)}$, K. MacKenzie ${ }^{(1)}$, D. Johnson ${ }^{(1)}$, R.J. Shul ${ }^{(2)}$, Y.B. Hahn ${ }^{(3) *}$, D.C. Hays ${ }^{(3)}$, C.R. Abernathy ${ }^{(3)}$, F. Ren ${ }^{(4)}$ and S.J. Pearton ${ }^{(3)}$

(1) Plasma-Therm, Inc., St. Petersburg, FL 33716, USA

${ }^{(2)}$ Sandia National Laboratories, Albuquerque, NM 87185, USA

${ }^{(3)}$ Department of Materials Science and Engineering University of Florida, Gainesville, FL 32611, USA

${ }^{(4)}$ Department of Chemical Engineering University of Florida, Gainesville, FL 32611, USA

\begin{abstract}
GaAs-based metal semiconductor field effect transistors (MESFETs), heterojunction bipolar transistors (HBTs) and high electron mobility transistors (HEMTs) have been exposed to ECR $\mathrm{SiH}_{4} / \mathrm{NH}_{3}$ discharges for deposition of $\mathrm{SiN}_{\mathrm{x}}$ passivating layers. The effect of source power, rf chuck power, pressure and plasma composition have been investigated. Effects due to both ion damage and hydrogenation of dopants are observed. For both HEMTs and MESFETs there are no conditions where substantial increases in channel sheet resistivity are not observed, due primarily to (Si-H) ${ }^{0}$ complex formation. In HBTs the carbon-doped base layer is the most susceptible layer to hydrogenation. Ion damage in all three devices is minimized at low rf chuck power, moderate ECR source power and high deposition rates.
\end{abstract}

\footnotetext{
${ }^{*}$ Permanent address: $\quad$ School of Chemical Engineering and Technology, Chonbuk National University, 664-14 Duckjin-Dong, 1-Ga, Chonju 561-756 Korea
} 


\section{DISCLAIMER}

This report was prepared as an account of work sponsored by an agency of the United States Government. Neither the United States Government nor any agency thereof, nor any of their employees, make any warranty, express or implied, or assumes any legal liability or responsibility for the accuracy, completeness, or usefulness of any information, apparatus, product, or process disclosed, or represents that its use would not infringe privately owned rights. Reference herein to any specific commercial product, process, or service by trade name, trademark, manufacturer, or otherwise does not necessarily constitute or imply its endorsement, recommendation, or favoring by the United States Government or any agency thereof. The views and

opinions of authors expressed herein do not necessarily state or reflect those of the United States Government or any agency thereof. 


\section{DISCLAIMER}

Portions of this document may be illegible in electronic image products. Images are produced from the best available original document. 


\section{INTRODUCTION}

Low damage deposition of dielectrics, particularly $\mathrm{SiN}_{\mathrm{x}}$, is a critical step in the processing of III-V devices such as metal semiconductor field effect transistors (MESFETs), heterojunction bipolar transistors (HBTs) and high elecitron mobility transistors (HEMTs). ${ }^{(1-14)}$ Examples include use of $\mathrm{SiN}_{\mathrm{x}}$ as a long-term encapsulant to protect against surface degradation, as a mask for etching to form mesas, and as a sidewall spacer during base mesa formation on HBTs. Most of the previous work has been performed with conventional rf-powered, low ion density reactors. ${ }^{(1,3,6,14)}$ More recently high density plasma tools have become popular for III-V device processing. ${ }^{(2,15,16)}$ Both the degree of plasma dissociation and the ion flux incident on the sample are higher than in low density tools. However there has been little work on the effects of ion damage or hydrogen passivation occurring during high density plasma deposition. There have been some reports on improved conformality of step coverage over high aspect-ratio features, such as T-gates on sub-micron HEMTs ${ }^{(14)}$, with high density plasma chemical vapor deposition (HDP-CVD).

In this paper we report on a detailed study of the effects of plasma deposition of thin $\mathrm{SiN}_{\mathrm{x}}$ films using the $\mathrm{SiH}_{4} / \mathrm{NH}_{3}$ chemistry on the dc device parameters of GaAs MESFETs, GaAs/AlGaAs HBTs and GaAs/InGaP HEMTs. The $\mathrm{SiN}_{\mathrm{x}}$ films were deposited by Electron Cyclotron Resonance (ECR)-CVD directly onto completed devices with a low enough thickness (200 ̊) that we could probe directly through to the underlying contacts. This eliminates any effects of having to remove the $\operatorname{SiN}_{\mathrm{x}}$ prior to testing. 


\section{EXPERIMENTAL}

The HEMT structures were grown by either conventional solid-source Molecular Beam Epitaxy (MBE) or Gas-Source MBE on semi-insulating GaAs substrates at $\sim 550^{\circ} \mathrm{C}$. To reduce impurities and defects in the active layers, a thick $(\sim 0.5 \mu \mathrm{m}) \mathrm{GaAs}$ buffer was deposited first, followed by a $400 \AA$ thick Si-doped $\left(\mathrm{N}_{\mathrm{D}} \sim 3 \times 10^{18} \mathrm{~cm}^{-3}\right)$ active donor layer. The structure was completed with a $300 \AA$ thick $\mathrm{n}^{+}\left(\mathrm{n} \sim 3 \times 10^{18} \mathrm{~cm}^{-3}\right) \mathrm{GaAs}$ contact layer. HEMTs were fabricated by the process described previously ${ }^{(4)}$, which involves AuGeNi source/drain ohmic contacts and a lift-off, TiPtAu, $1 \mu \mathrm{m}$ gate length rectifying contact.

GaAs MESFETs were fabricated using lift-off TiPtAu gate contacts and AuGeNi source/drain contacts. Gate length was $1 \mu \mathrm{m}$ with a gate width of $30 \mu \mathrm{m}$. The channel and source/drain doping was created by $\mathrm{Si}^{+}$implantation followed by $900^{\circ} \mathrm{C}, 30 \mathrm{sec}$ rapid thermal annealing of initially semi-insulating substrates.

The GaAs/AlGaAs HBTs were grown by metal Organic Molecular Beam Epitaxy (MOMBE), as described previously. ${ }^{(17-19)}$ Briefly, the base layer is $700 \AA$ thick, doped to $7 \times 10^{19} \mathrm{~cm}^{-3}$ with carbon. The full structure consisted of $6000 \AA$ of Sn-doped $\left(\mathrm{n}=3 \times 10^{18} \mathrm{~cm}^{-3}\right)$ GaAs sub-collector, $7000 \AA$ of $C$-doped $\left(\mathrm{p}=7 \times 10^{18} \mathrm{~cm}^{-3}\right)$ GaAs base, $800 \AA$ of Sn-doped

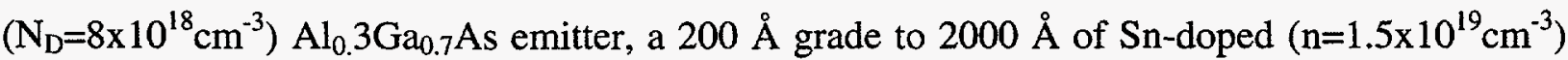
GaAs emitter contact layer, and a $300 \AA$ grade to $300 \AA$ of Sn-doped $\left(\mathrm{n}=3 \times 10^{19} \mathrm{~cm}^{-3}\right) \mathrm{In}_{0.5} \mathrm{Ga}_{0.3} \mathrm{As}$ contact layer. Large area ( $80 \mu \mathrm{m}$ diameter) emitter devices were fabricated by wet etching, with non-alloyed TiPtAu base metallization and AuGeNi for emitter and sub-collector contacts.

Single layers of $\mathrm{n}, \mathrm{n}^{+}$and $\mathrm{p}^{+}$GaAs and AlGaAs were also grown on semi-insulating GaAs substrates by MOMBE (doping of $2 \times 10^{17} \mathrm{~cm}^{-3}-3 \times 10^{18} \mathrm{~cm}^{-3}$ for $\mathrm{n}$-type material, and 
$5.5 \times 10^{19} \mathrm{~cm}^{-3}$ for $\mathrm{p}^{+}$material) in order to measure sheet resistance and carrier mobility without the complication of multiple layers.

Deposition of $\mathrm{SiN}_{\mathrm{x}}$ was performed in a Plasma-Therm SLR 770 system, with the samples thermally bonded to a mechanically clamped Si carrier wafer. The plasma was created in a Wavemat 4400 low profile ECR source operation at $2.45 \mathrm{GHz}$ and powers of $150-700 \mathrm{~W}$. The sample chuck was rf-biased to produce a dc self-bias of $-5 \mathrm{~V}$. $\mathrm{SiH}_{4} / \mathrm{NH}_{3}$ was employed for all depositions, with the gases directed into the source through mass flow controllers at a total flow rate of 25 standard cubic $\mathrm{cm} \mathrm{min}^{-1}(\mathrm{sccm})$. The chuck temperature was varied from $25-120^{\circ} \mathrm{C}$, pressure from 15-40 mTorr, $\mathrm{SiH}_{4}$ percentage from 20-50\% and Ar flow from 0-20 sccm.

\section{RESULTS AND DISCUSSION}

The net effect of both hydrogen passivation of dopants and creation of deep level trap states by ion bombardment should be a decrease in carrier density. Figure 1 shows the influence of deposition temperature on the electrical properties of $n-G a A s$ on which $\operatorname{SiN}_{\mathrm{x}}$ was deposited at 10 mTorr with $10 \mathrm{~W}$ rf chuck power and $800 \mathrm{~W}$ ECR source power. There is a slight decrease in electron concentration at the higher temperatures, suggesting there is some hydrogen passivation of the Si dopants. This would be more obvious at higher temperatures due to the higher atomic hydrogen diffusivity. In $\mathrm{n}^{+} \mathrm{AlGaAs}$ (Figure 2) there is a strong passivation effect at $200^{\circ} \mathrm{C}$, whereas at higher temperatures the $(\mathrm{Si}-\mathrm{H})^{0}$ neutral complexes are not stable and there is no effect on the electrical properties.

Hydrogen effects were stronger in both $\mathrm{p}^{+}$GaAs and AlGaAs. An example is shown in Figure 3 for AlGaAs. The proof of hydrogenation is the corresponding increase in hole mobility 
- if deep level compensation were the cause of the carrier reduction then mobility would decrease.

Figure 4 shows the effect of deposition temperature on GaAs/AlGaAs HBT emitter-base breakdown voltage $\left(\mathrm{V}_{\mathrm{EB}}\right)$, base-collector breakdown voliage $\left(\mathrm{V}_{\mathrm{BC}}\right)$, ideality factor of the emitterbase junction, and the device current gain for $\mathrm{SiH}_{4} / \mathrm{NH}_{3}$ discharges $(15 \mathrm{~m}$ Torr, $350 \mathrm{~W}$ source power). The current gain drops rapidly above $100^{\circ} \mathrm{C}$, which may be related to the more efficient passivation of Si donors in the collector as hydrogen diffusion is higher and more of this layer can be affected. Note also under these conditions that $V_{B C}$ and $V_{E B}$ are decreased and the emitter-base junction ideality factor is increased. Clearly, the deposition temperature should be minimized for this chemistry.

Increasing the ECR source power increases the dissociation fraction of the reactants and also the ion density. Figure 5 shows that there is an optimum window of powers around $350 \mathrm{~W}$ where $\mathrm{HBT}$ gain is a maximum, $n_{\mathrm{EB}}$ is a minimum and both $\mathrm{V}_{\mathrm{BC}}$ and $\mathrm{V}_{\mathrm{EB}}$ are still reasonably close to their control values for the $\mathrm{SiH}_{4} / \mathrm{NH}_{3}$ plasma chemistry. At higher source powers there may be too high a flux of $\mathrm{H}_{2}{ }^{+}, \mathrm{H}^{+}$and other ions, and too much neutral atomic hydrogen present, which lead to device degradation.

Figure 6 shows the variation of GaAs MESFET dc parameters on chuck temperature during ECR-CVD of $\mathrm{SiN}_{x}$ using the $\mathrm{SIH}_{4} / \mathrm{NH}_{3}$ chemistry. Threshold voltage improves with deposition temperature up to $100^{\circ} \mathrm{C}$, but is severely degraded at $120^{\circ} \mathrm{C}$. The same trend is observed in breakdown voltage, while these first two parameters are in anti-correlation with gate ideality factor and transconductance. While the additional dc bias on the cathode is only $-5 \mathrm{~V}$, there is a plasma potential of -20 to $-30 \mathrm{~V}$ so that incident ions will have maximum energies of 25 to $-35 \mathrm{~V}$, sufficient to create displacement damage that can reduce the effective channel 
doping. Moreover, atomic hydrogen from dissociation of the $\mathrm{SiH}_{4}$ and $\mathrm{NH}_{3}$ can passivate the $\mathrm{Si}$ doping in the channel through the reaction ${ }^{(20)}$

$$
S i^{+}+H^{-} \rightarrow(S i H)^{o}
$$

Therefore we believe the combined effects of ion damage and dopant passivation account for the observed device degradation. Dynamic annealing of ion-induced point defects as the sample temperature is increased leads to improved date diode ideality factors, but at higher temperatures there is more efficient passivation of the Si donors because of the higher diffusivity of hydrogen. Moreover, at the highest deposition temperature preferential loss of As from the surface may occur through the reaction

$$
\mathrm{As}+3 \mathrm{H} \rightarrow \mathrm{AsH}_{3} \uparrow
$$

and this accounts for the reduction in breakdown voltage.

The source power during deposition controls the degree of plasma dissociation and the incident ion flux. Figure 7 shows the dependence of MESFET parameters on ECR source power during $\mathrm{SiN}_{\mathrm{x}}$ deposition using $\mathrm{SiH}_{4} / \mathrm{NH}_{3}$. Ideality factor degrades rapidly at high powers due to high gate contact periphery damage, while transconductance monotonically decreases under the same conditions. The MESFET breakdown voltage is not as strongly dependent on source power, but the device threshold voltage switches from negative to positive values as the source power increases. Clearly moderate-to-low powers are preferable for deposition on MESFETs, especially in the initial stages where the surface is still exposed. It may be possible to use higher powers once the surface is completely covered.

Figure 8 shows the effect of source power during deposition on $n, g_{m}, \mathrm{~V}_{\mathrm{T}}$ and $\mathrm{V}_{\mathrm{B}}$ for a $\mathrm{GaAs} / \mathrm{InGaP}$ HEMT. Note that all of these parameters improve with source power for the $\mathrm{SiH}_{4} / \mathrm{NH}_{3}$ plasma chemistry. At low ECR powers the discharge behaves more like a 
conventional low density plasma. Even though the sample position was nominally biased with $5 \mathrm{~V} \mathrm{dc}$ through application of a small $\mathrm{rf}(13.56 \mathrm{MHz})$ power, the average ion energy will still be in the $20-30 \mathrm{eV}$ range because of the plasma potential. Increasing the ion density reduces this slightly, and so the main effect of increasing source power is most likely to increase the deposition rate and thereby cover the surface more quickly and protect against hydrogen incorporation and ion bombardment. It was previously reported by Seaward ${ }^{(3)}$ that hydrogen passivation effects were reduced in high-deposition rate processes.

\section{SUMMARY AND CONCLUSIONS}

The main results of the HBT studies were as follows:

(i) Deposition temperature had a strong effect on device performance for the $\mathrm{SiH}_{4} / \mathrm{NH}_{3}$ chemistry.

(ii) $\mathrm{SiH}_{4}$-rich conditions are desirable suggesting much of the hydrogen in the $\mathrm{SiH}_{4} / \mathrm{NH}_{3}$ mixture originates from the ammonia.

(iii) Moderate ECR source powers are desirable and one should avoid the very high active neutral and ion fluxes present at powers above $\sim 500 \mathrm{~W}$.

(iv) Deposition pressures around 15 mTorr produce the least HBT device degradation, probably by minimizing hydrogen passivation of dopants and ion-induced damage which are prevalent at higher and lower pressures, respectively.

(v) Addition of Ar to the deposition chemistry should be avoided, since it leads to HBT device performance fall-off even at low flow rates. 
For GaAs MESFETS, the main results were:

(i) High pressures, high ECR source powers, high deposition temperatures and high $\mathrm{SiH}_{4}$ contents all lead to more MESFET degradation, which again can be understood in terms of relative amounts ô̂ hydrogen ions and neutrals that lead to ion-induced damage or dopant passivation in the device.

(ii) For deposition of $\mathrm{SiN}_{\mathrm{x}}$, the $\mathrm{SiH}_{4} / \mathrm{N}_{2}$ chemistry (not discussed here) induces less device degradation than $\mathrm{SiH}_{4} / \mathrm{NH}_{3}$ under the same conditions. This appears to be due to the lower hydrogen content in the plasma, which can exacerbate changes in the device performance through $\mathrm{Si}-\mathrm{H}$ complex formation and by $\mathrm{H}_{2}{ }^{+}$and $\mathrm{H}^{+}$ioninduced damage.

For GaAs/InGaP HEMTs the main results were:

(i) Higher ECR source powers produce less effect on HEMT dc parameters than low source powers under our conditions. We have deliberately kept the ion energy (i.e. rf-biasing of the sample position) low since our previous studies on dry etching of HEMTs under high density plasma conditions showed that rf chuck powers above $25 \mathrm{~W}$ produced extreme degradation of both GaAs/AlGaAs and GaAs/InGaP HEMTs.

(ii) Deposition pressures above 20 mTorr are preferred to minimize reduction in HEMT dc performance. This appears to be a result of the higher deposition rate, which protects the exposed AlGaAs donor layer from hydrogen indiffusion and from ion bombardment damage. 


\section{ACKNOWLEDGEMENTS}

The work at UF is partially supported by a DOD MURI monitored by AFOSR (H.C. DeLong), contract no. F49620-96-1-0026. Sandia National Laboratories is a multi-program laboratory operated by Sandia Corporation, a Lockheed-Martin company, for the United States Department of Energy under contract no. DE-AC04-94AL85000. Y.B. Hahn gratefully acknowledges the support of Korea Research Foundation. 


\section{REFERENCES}

1. C.S. Wu, G.L. Lan, C.K. Pao, S.X. Bur and M. Hu, Mat. Res. Soc. Symp. Proc. $\underline{300}, 14$ (1993).

2. R.J. Shul, A.J. Howard, C.B. Vartuli, P.A. Barnes and W. Seng, J. Vac. Sci. Technol. A 14, $1102(1996)$.

3. K.L. Seaward, Appl. Phys. Lett. $\underline{6}$, 3002 (1992).

4. F. Ren, D.N. Buckley, K.N. Lee, S.J. Pearton, R.A. Bartynski, C. Constantine, W.S. Hobson, R.A. Hamm and D.C. Chao, Solid-State Electron. 38, 2011 (1996).

5. F. Ren. J.R. Lothian, S.J. Pearton, C.R. Abernathy, P.W. Wisk, T.R. Fullowan, B. Tseng, S.N.G. Chu, Y.K. Chen, L.W. Yang, S.T. Fu, R.S. Brozovich, H.H. Lin, C.L. Henning and T. Henry, J. Vac. Sci. Technol B 12 , 2916 (1994).

6. B. Bayraktaroglu, Solid-State Electron. 41, 1657 (1997).

7. R. Anholt, Solid-State Electron. 41, 1735 (1997).

8. J.H. Ning, J.S. Yuan and J. Song, Solid-State Electron. 41, 1263 (1997).

9. K. Yang, G.O. Munns and G.I. Haddad, IEEE Electron Dev. Lett. EDL-18, 553 (1997).

10. W.L. Chen, H.F. Chern, M. Tutt, M.C. Ho, T.S. Kim and T. Henderson, IEEE Electron. Dev. Lett. EDL-18, 355 (1997).

11. M. Hafizi, IEEE Electron Dev. Lett. EDL-18, 358 (1997).

12. B. Agarwal, D. Mensa, R. Pullela, Q. Lee, V. Bhattacharya, L. Samoska, J. Guthrie and M.J.W. Rodwell, IEEE Trans. Electron. Dev. Lett. EDL-18, 228 (1997).

13. R. Hajii and F.M. Ghannouchi, IEEE Trans. Electron Dev. ED-44, 723 (1997).

14. C.-W. Kim, N. Hayama, N. Goto and K. Honjo, IEEE Electron. Dev. Lett. EDL-18, 147 
15. S.W. Pang, S. Thomas III and H.H. Chen, Appl. Surf. Sci. 117/118, 758 (1997).

16. C.R. Eddy, O.J. Glembocki, S.W. Pang, V.A. Shamamian, D. Leonhardt and J.E. Butler, J. Electron. Mater. $\underline{26}, 1320$ (1997).

17. C.R. Abernathy, J. Vac. Sci. Technol. A11, 869 \{1993).

18. C.R. Abernathy, Mat. Sci. Eng. Rep. R14, 203 (1995).

19. C.R. Abernathy, Mat. Res. Soc. Symp. Proc. $\underline{300,3} 3$ (1993).

20. S.J. Pearton, J.W. Corbett and T.S. Shi, Appl. Phys. A433, 153 (1987). 


\section{FIGURE CAPTIONS}

Figure 1. Effect of deposition temperature on resistivity, mobility and electron concentration in $\mathrm{SiN}_{\mathrm{x}}$-deposited $\mathrm{n}$-GaAs $(10 \mathrm{mTorr}, 800 \mathrm{~W}$ source power, $10 \mathrm{~W} \mathrm{rf}$ power). The data normalized to the control values are shown by open circles.

Figure 2 Effect of deposition temperature on resistivity, mobility and electron concentration in $\mathrm{SiN}_{\mathrm{x}}$-deposited $\mathrm{n}^{+} \mathrm{AlGaAs}(10 \mathrm{mTorr}, 800 \mathrm{~W}$ source power, 10 W rf power). The data normalized to the control values are shown by open circles.

Figure 3. Effect of deposition temperature on resistivity, mobility and electron concentration in $\mathrm{SiN}_{\mathrm{x}}$-deposited $\mathrm{p}^{+} \mathrm{AlGaAs}(10 \mathrm{mTorr}, 800 \mathrm{~W}$ source power, 10 $\mathrm{W}$ rf power). The data normalized to the control values are shown by open circles.

Figure 4. Variation of $\mathrm{HBT}$ gain, $n_{E B}, V_{\mathrm{BC}}$ and $V_{\mathrm{EB}}$ with $\operatorname{SiN}_{\mathrm{x}}$ deposition temperature in $\mathrm{SiH}_{4} / \mathrm{NH}_{3}$ discharges.

Figure 5. Variation of HBT gain, $n_{E B}, V_{\mathrm{BC}}$ and $V_{\mathrm{EB}}$ with ECR source power in $\mathrm{SiH}_{4} / \mathrm{NH}_{3}$ discharges. 
Figure 6. Variation of gate diode ideality factor $(n)$, breakdown voltage $\left(V_{\mathrm{B}}\right)$, threshold voltage $\left(V_{\mathrm{T}}\right)$ and transconductance $\left(g_{\mathrm{m}}\right)$ for GaAs MESFETs exposed to $\mathrm{SiH}_{4} / \mathrm{NH}_{3}$ ECR discharges as a function of chuck temperature.

Figure 7. Variation of $n, V_{\mathrm{B}}, V_{\mathrm{T}}$ and $g_{\mathrm{m}}$ for GaAs MESFETs exposed to $\mathrm{SiH}_{4} / \mathrm{NH}_{3}$ ECR discharges as a function of source power.

Figure 8. Variation of $n, g_{\mathrm{m}}, V_{\mathrm{T}}$ and $V_{\mathrm{B}}$ as a function of source power for GaAs/InGaP HEMTs deposited with $\operatorname{SiN}_{\mathrm{x}}$. 

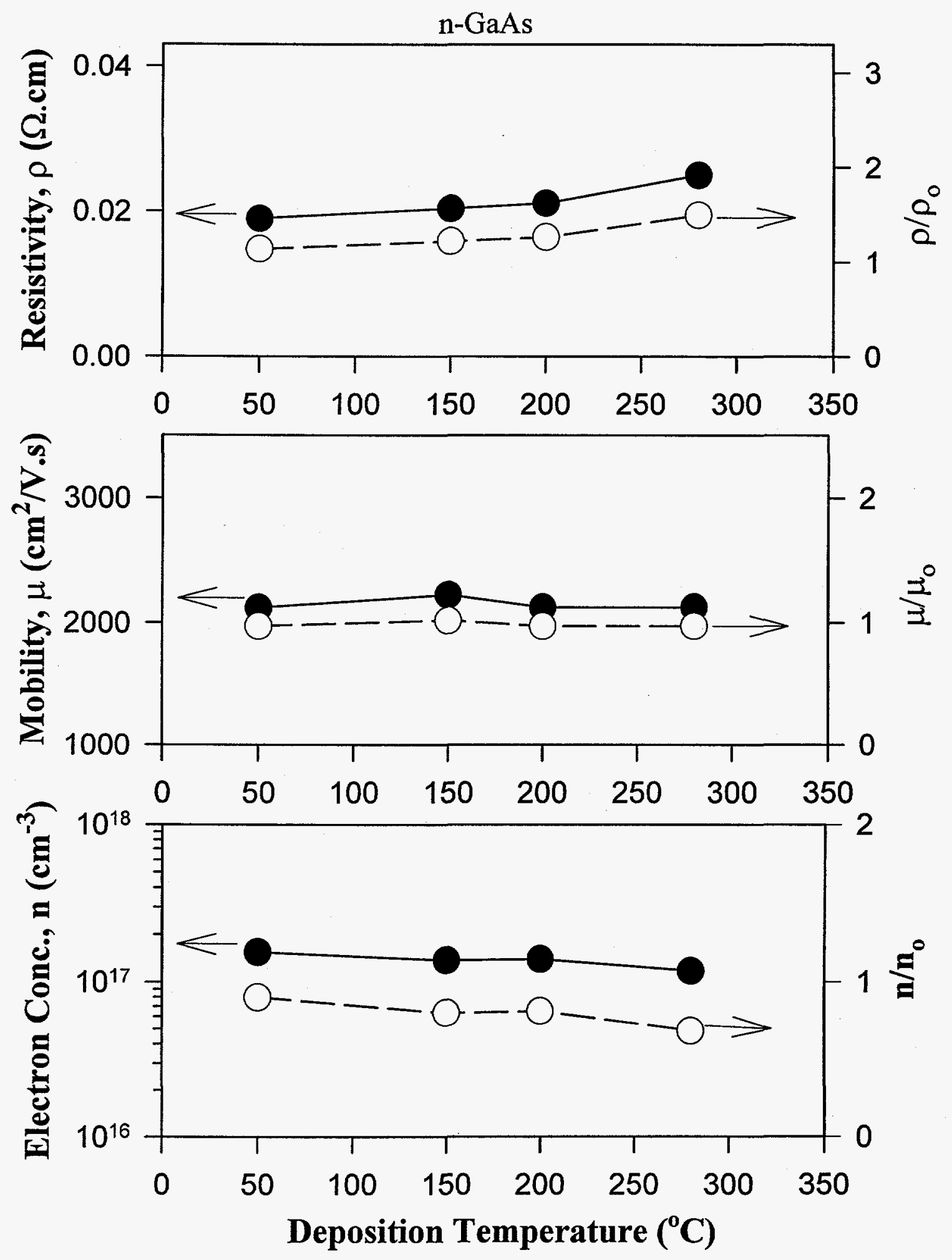


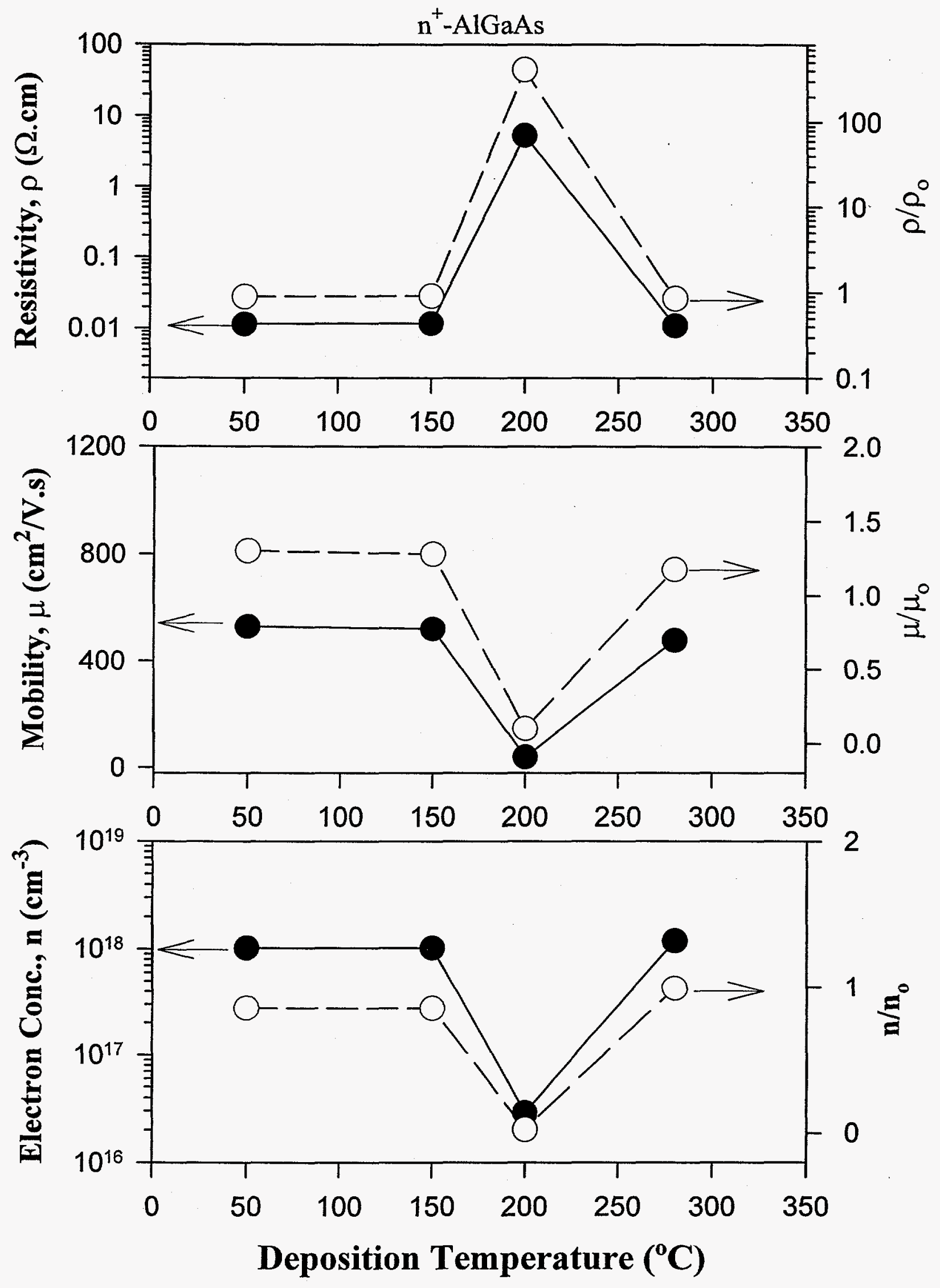



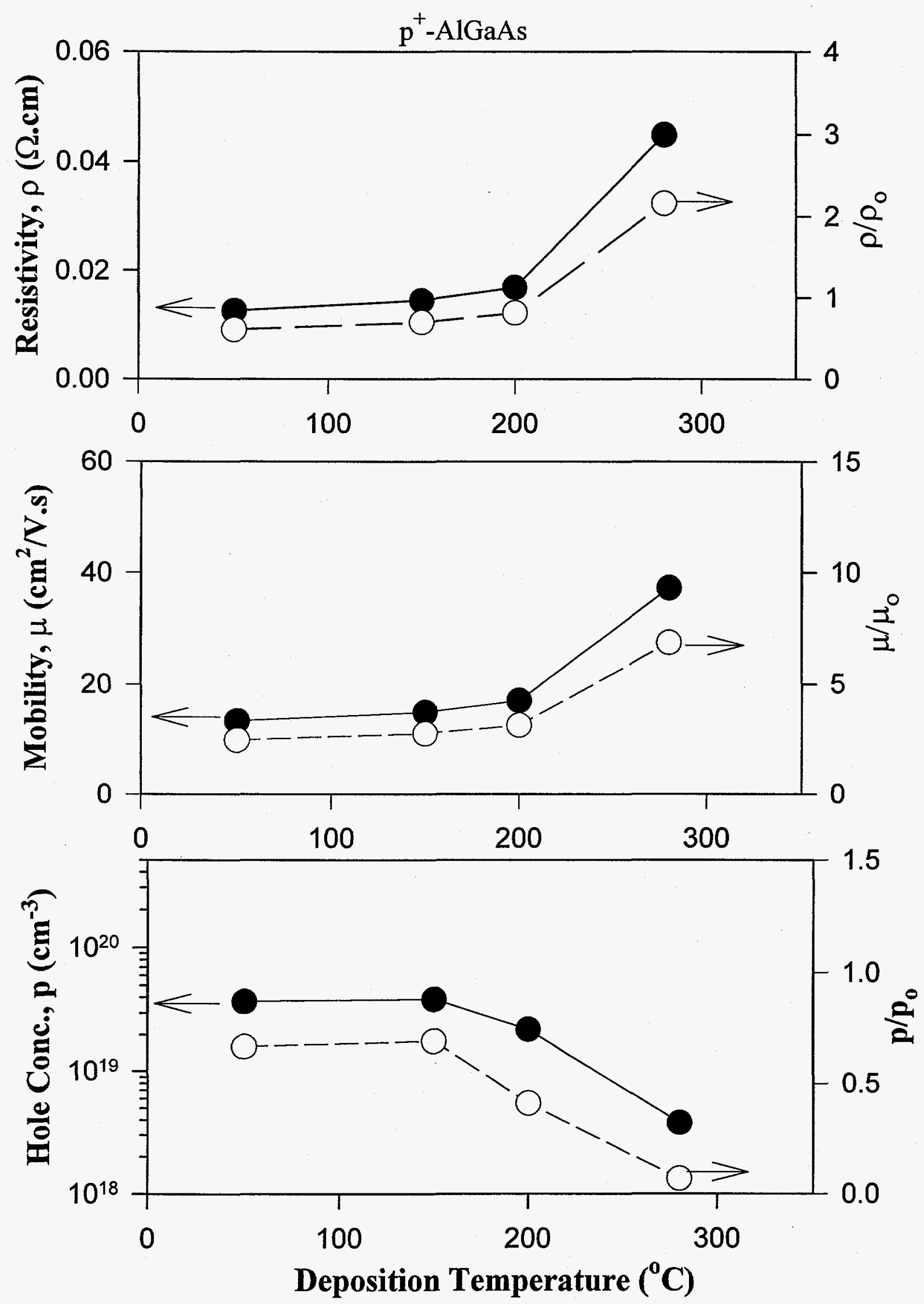


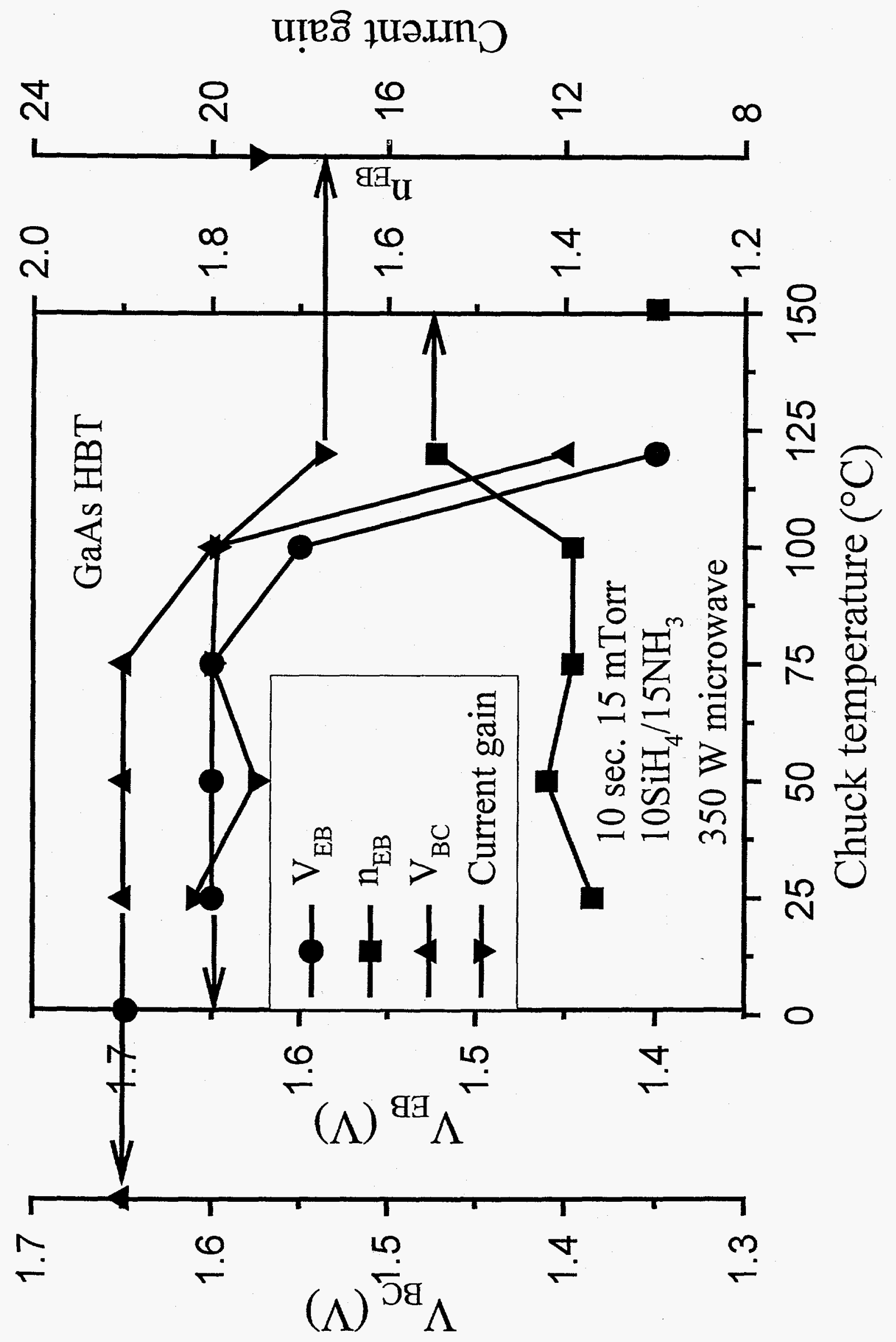




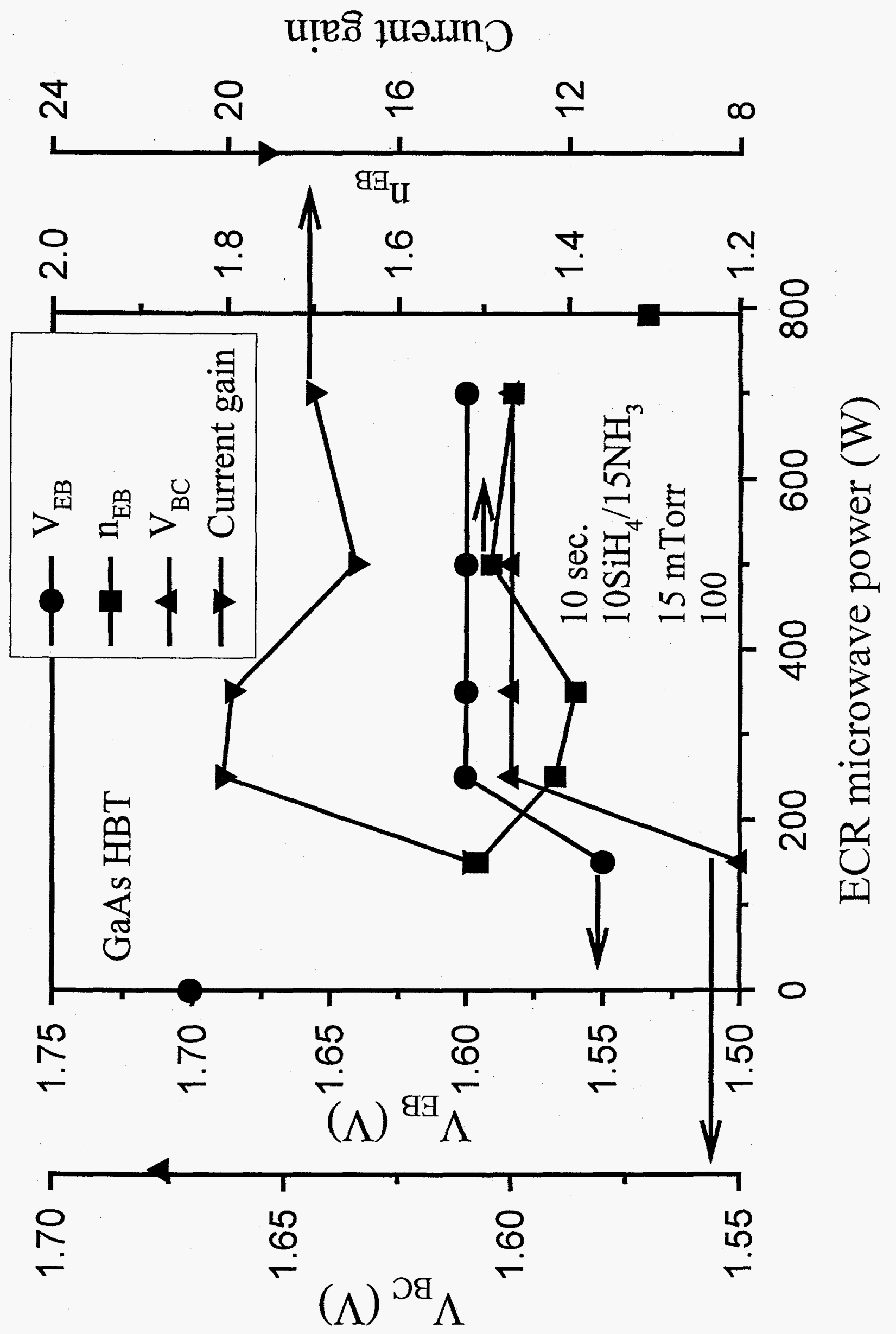


Ideality factor

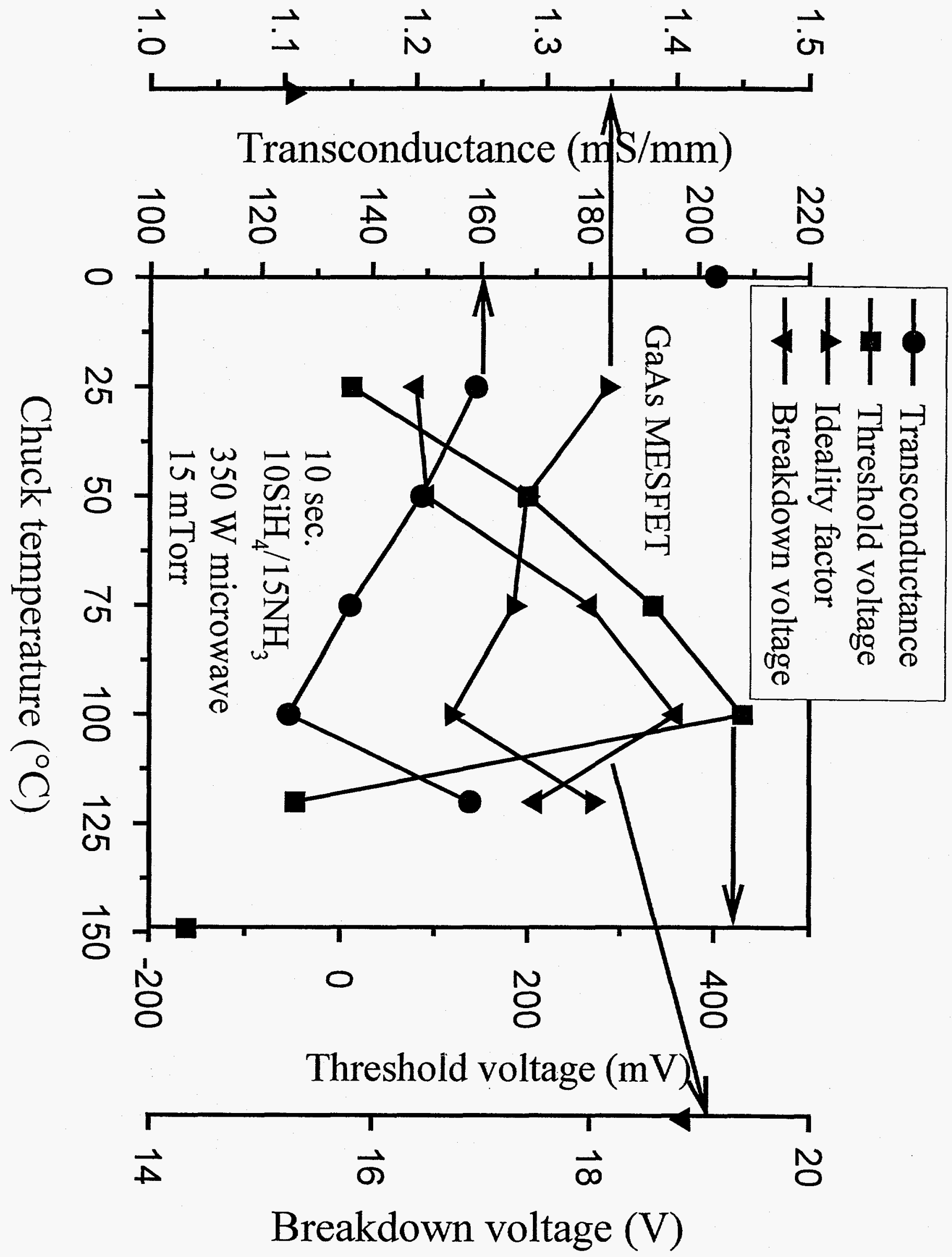




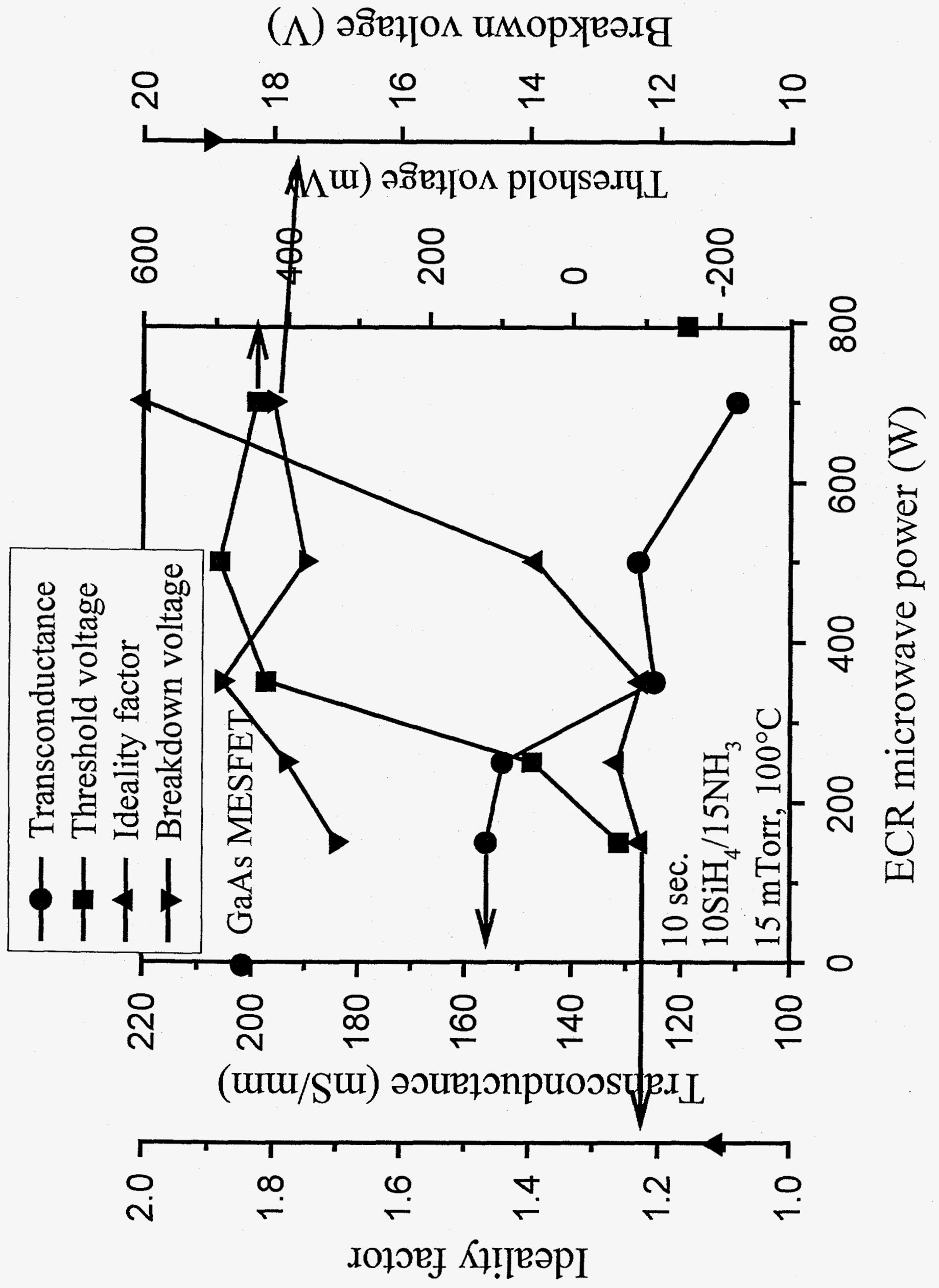




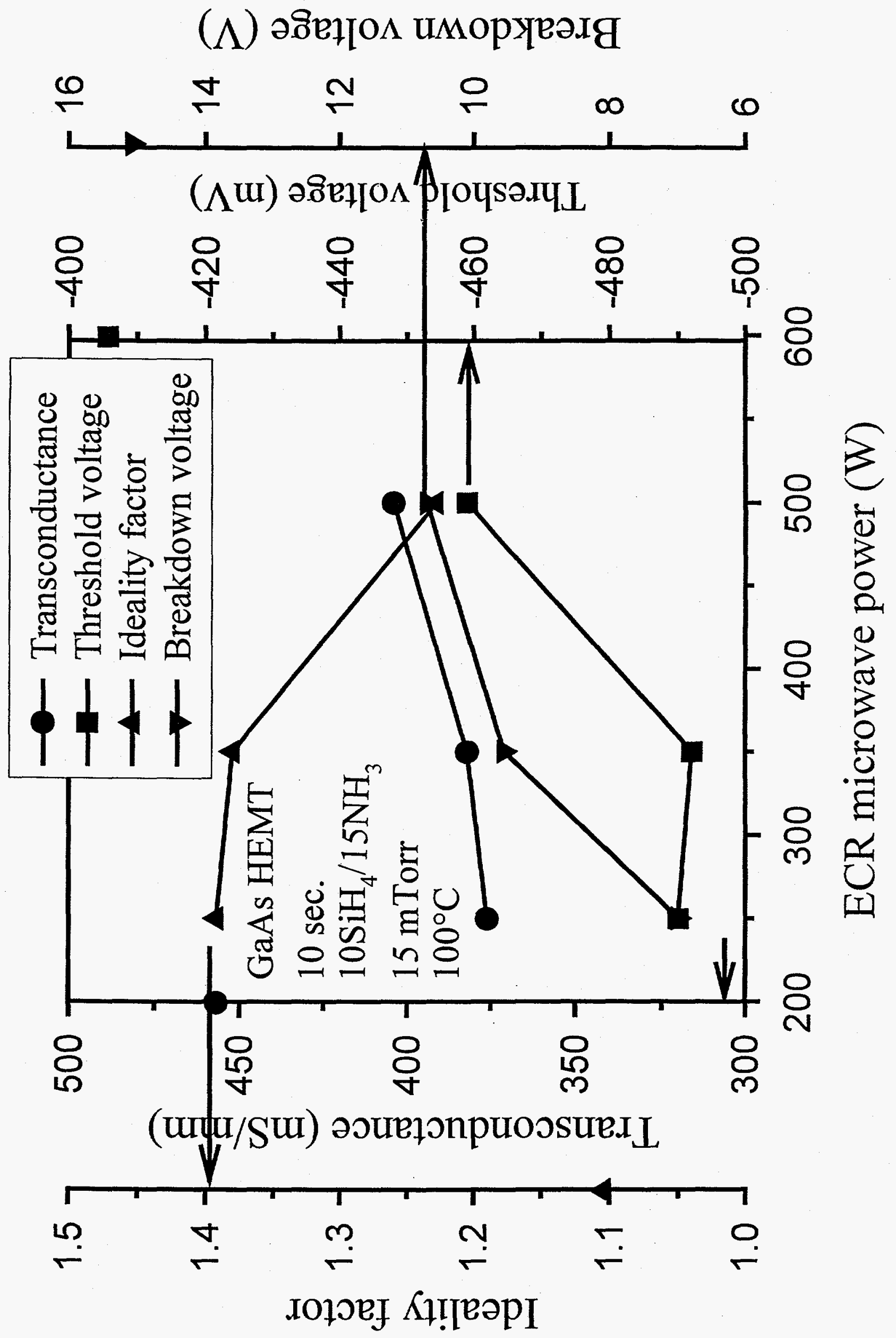

